\title{
THE DESCRIPTION OF NEW
}

\section{SPECIES OF THE GENUS}

\section{PSEUDONAPAEUS}

\author{
(GASTROPODA,
}

\section{PULMONATA, GEOPHILA) FROM KUGITANGTAU MOUNTAIN RANGE}

\author{
Gaipnazarova Feruza \\ Gulistan state University 4 microdistrict, Gulistan, 120100 \\ Uzbekistan Feruz.bio@mail.ru
}

\begin{abstract}
During studying of land mollusks of Kugitangtau mountain range ( marine fauna which is learnt partly, comparatively whith other
\end{abstract}


mountain systems of Central Asia ) in the bound of one hill, on one side of slope, under one stone in common with Ps.sogdiana a new species is displayed which is similar to it . The further studying of konhological signs and structure of reproductive apparatus let the author reveal a new species of the new type of the genus Pseudonapaeus.

Key words: Kugitangtau, Konchologiya, changeness, shell, spermathecal reservoir, whip, penial appendix, epiphallaus, caecum.

The genus of Pseudonapaeus ( Westerlund, 1887 ) is on the first place ona number of types in marine fauna of Central Asia which has 34 species belong to 4 subgenus : Pseudonapaeus (Schileyko,1984) sirahorus ( Schileyko, 1984) , Aridenus (Schileyko, 1984), Chondrulopsis (Westerlund, 1887 ). The most numbers (28) of species belong to subspecies Pseudonapaeus, Chondrulopsis (4), by 1 sirahorus and Aridenus.

For the first time detailed description of shell and anatomy of the reproductive structure of Pseudonapaeus was distributed by A.A.Schileyko(1984), he gives the description to 13 species, one of them has in species changeness of Ps.albiplicatus at least distributing large complex of conchological (8) forms, distinguishing sometimes solely at once.

We should mention that last 20-25 years a deal of works were published (Uvalieva 1990, Kuznetsov 1999, Pazilov, Azimov 2003) on malacofauna of Central Asia, in which representatives of the genus Pseudonapaeus is filled up else 10 new species for science.

Impetuous filling of this genus by new genus for science shows that the genus Pseudonapaeus in Central Asia is not studied insufficiency yet.

Besides this, Schileyko (1984) mentions that main ecological niche filled long ago in the Crimea, in the Caucasus and in Central Eurpe,where eac species is separated clearly from close species and we may say, that process of modification is finished.In Central Asia,he process of modification in our days goes more intensive than in the Crimea, in the Caucasus.Fox 
example on Chatkal mountain range of Gavasay canyon Pseudona paeus secalina,Ps. Subobscura are met together clearly separated without any transitions, these types behave here as good species. But the same taxons on Turkestan mountain range behave in onother way on the limited space of canyon you may pick collection which will contain real Ps. Secalina, Ps subobscura and various types between them.

That is why when the report is about new tax one from Central Asia first the changeless of close species will be studied.

For example one of the same species (Ps. Albiplicata is very changeable) in two bio lands are not for from each other good reflected some factors can be firmly distinguished $b$ other sings.

Evidently, it is connected with typical peculiarity; it is extra-ordinary diversity of colours of microclimatic, soil, metrological, geochemical and natural conditions in micro landscapes of explored region which is very being old on neighbors sections of genus changeless.

The second, absolutely reliabk information about what Concho logical sorts inhabit together in the area of one bio land.

The third it is need spacious additional collections and anatomizing of mass material.

The forth besides availability or absence of separate elements of reproductive apparatus (spermathecaldiverticle, whip, penial appendix, caecum) it is ndd to study insicle structure of male part which ives reliable information for purpose of systematic.

During the reproductive seasons of 2013 year one of us (by A.Pazilov) collections of land mollusks on Kugitangtau mountain range are spent, marine fauna comparatively with other mountainssytems of CentralAsia is studied fragmentary and scrappy. In addition, central and western parts until present times are being left unstudied.

In central part of Kugitangtau, in Maydan canyon, in the area of one homogeneous part of slope, under one stone with Ps.sogdiana togother is found out species, which is similar to it. 
However, it is turned out that it is a new species for the science during the studying of conchological signs and structure of productive apparatus.

These facts are became the the occasion for the description of new taxone from genus Pseudonapaeus

Pseudonapaeus (Pseudonapaeus) maydanica

Gaibnazarova end Pazilov, sp.nov.

Locus typicus Southern slope of Kugitangtau, Mayday canyon among bushes

Material Holotype (№ 1 in systematic collection) and 25 paratypes № 2 are kept in the zoological museum of Gulistan state University.

Etymology - the name is given in conformity to the name of place of find - Maydan canyon.

Description. Shell bullet - lengthen shining moderately solid with conic short upper part and wide curvedapex. Composed of $6-6,5$ flattened - building whorls. Last whorl to the mouth is weakly raised, its height always visibly higer of half height of shell. Colour of three upper whorls is light brown, others are creamy - white surface is in type of rough radial wrinkling . Mouth oval - lengthen, margins are very weakly turned back, place of fasten of the mouth are connected with good developed corn.

Inside structure . Material 6 copies ( Holotype and 5 paratypes ) from Maydan canyon.

Albuminous gland with very fluent apic carving, lower part of vagina two times shorter than upper part. Vas deferens confluences in to epiphallus eccentricly but absolutely is not moved low by epiphallus.

Cylindrical epiphallus is differ from considerable length forms one bend. Caecum is developed in different steps, it is approximately in the middle of epifallus, sometimes caecum is badly noticed. Epiphallus confluences into penis not terminally but a little at the side. Penis is cylindrical, inside of penis there are some powerful corrugated wrinkles penial appendix is developed in different steps A1 and A2 are connected in one pinform part the length of which is not upper the length of penis, 
A3 is very short and smoothly comes through very long A4. A5 is good developed.

Penial branch of penial retractor is hold with lower part of penis, the second branch - with upper part of A1 .

Part of spermathecal is long formed twice loop and exceeds the length of vagina considerably.

Reservoir has very short part the length that is one and half times shorter than reservoir. Spermathecal diverticle good developed, not enters to albumen gland a little.

Remark Conchological new species is differed from close Ps(Ch.) sogdiana ( Matens, 1874) bright shell, sharpen a little conic peak, upper three whorls always light brown, in other whorls radial diversity of colours are absent, mouth is squinted more, the place of connection of the mouth is connected with good formed corn, collumeleric edge is sheered.

Anatomically Ps(Ps. ) maydanica is differed from Ps ( Ch). sogdiana albumen gland with apical carve prostate is $14,5 \mathrm{~mm}$, caecum very weakly formed and always is in the middle of epiphallus, inside penis contains of powerful cornugated wrinkles, A1 and A2 are always connected in one pinform part, spermathecal part formed twice loop.

Ecology, It is met in upper mountain and mountainuous zones, ------- in huge fragmental covers, among overgrowth bushes.

Spreading. Species is famous from typical location on the southern slope ( central part ) of Kugitangtau mountain range, in Maydan canyon.

1. Kuznetsov A.G new facts about Land mollusks of Enidae (Gostrapoda, Pulmonota ) family of Central Asia // Ruthenica -9, № 2. - C. 101-102

2. Pazilov A., Azimov D.A Land mollusks ( Gostrapoda, Pulmonata ) of Uzbekistan and surraounding territories. - Tashkent : Science, 2003. - 315 p. 
3. Uvaliyeva K.K Land mollusks of Uzbekistan and surrounding territories. Alma-Ata. Science Kaz. SSR, 1990. - 224c.

4. Shileyko A.A Land mollusks of the group Pupillina of the Fauna of U SSR ( Gostrapoda, Pulmonata, Geophila ) Fauna of the U SSR. Mollusks - L.: Science Lenengrad Department, 1984. T.Z. 3 . № 130. - 399 C.

\section{Pseudonapaeus ( Pseudonapaeus) maydanica Gaibnazarova end Pazilov, sp.nov.}

Navel is as split. Sizes(мм):

\begin{tabular}{|c|c|c|c|c|}
\hline $\begin{array}{c}\text { Height of } \\
\text { shell }\end{array}$ & $\begin{array}{c}\text { Width of } \\
\text { shell }\end{array}$ & $\begin{array}{c}\text { Height of } \\
\text { mouth }\end{array}$ & $\begin{array}{c}\text { Width of } \\
\text { shell }\end{array}$ & $\begin{array}{c}\text { Number of } \\
\text { whoris }\end{array}$ \\
\hline \multicolumn{5}{|c|}{ Holotype } \\
\hline 18.1 & 7.8 & 7 & 5.3 & 6.5 \\
\hline \multicolumn{5}{|c|}{ Paratype } \\
\hline 17 & 7 & 6 & 5 & 6 \\
\hline 16.1 & 7 & 6.1 & 5 & 6 \\
\hline 16.3 & 7 & 6.9 & 5.1 & 6 \\
\hline 16.8 & 7 & 7 & 5 & 6.5 \\
\hline 17.1 & 7 & 6.9 & 5 & 6.5 \\
\hline
\end{tabular}

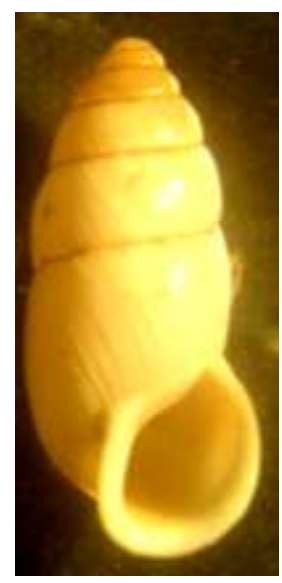

Health Sciences

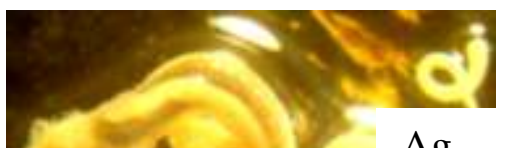

$\mathrm{Ag}$

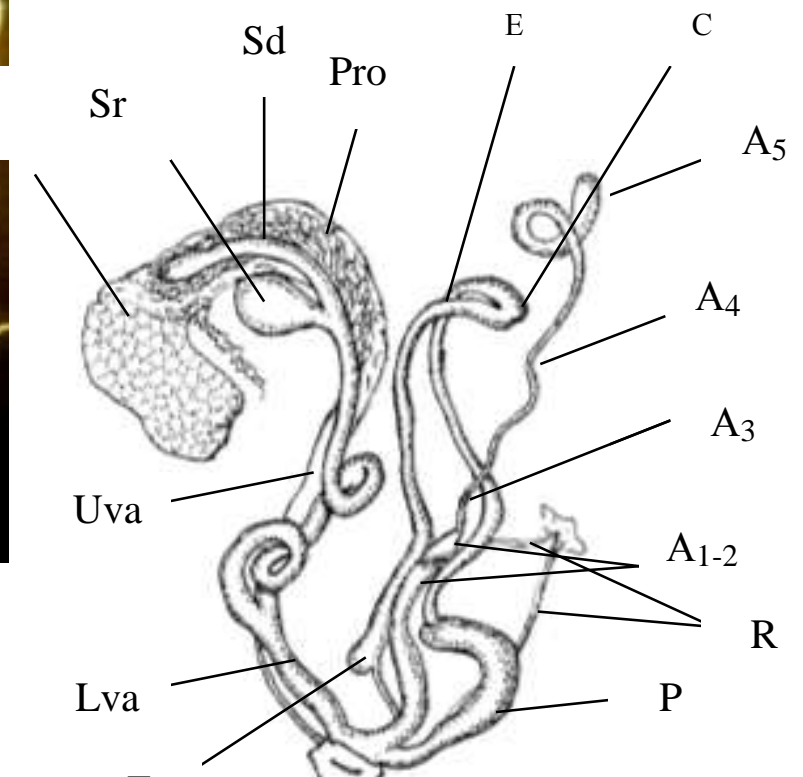


A $\quad$ B $\quad$ C

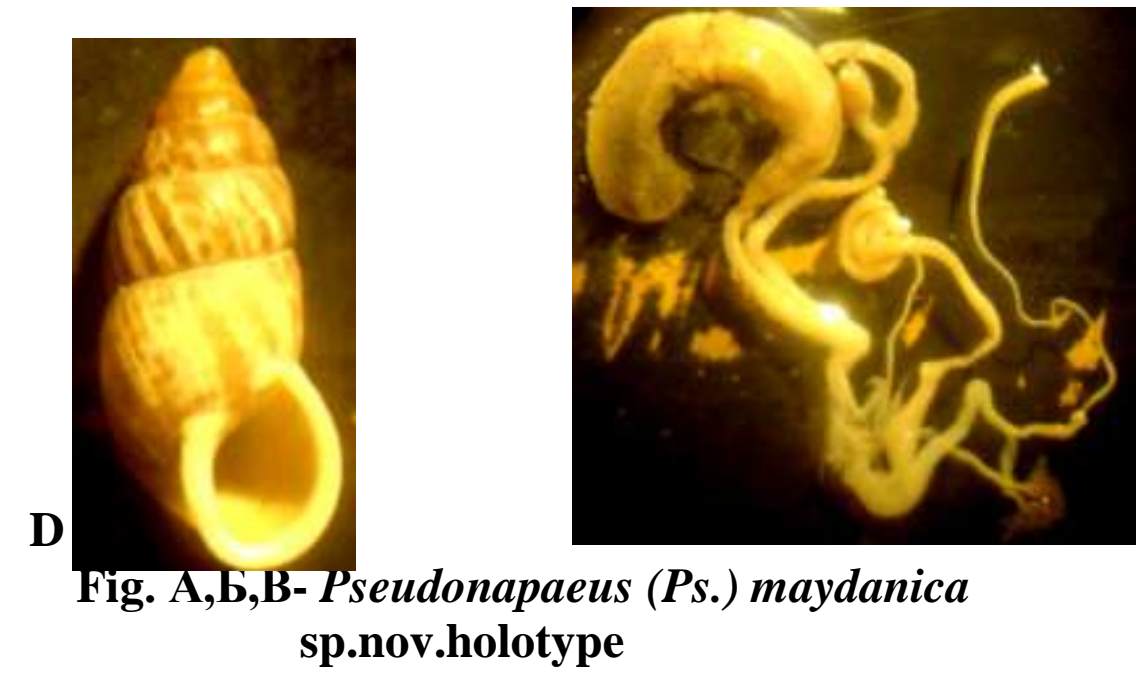

\section{Д,Е- Ps. (Ch.) sogdiana}

A-shell; B,C -reproductive apparatus.

Ag- albumen glang; Pro- prostate; $\mathrm{A}_{1}-\mathrm{A}_{5}$ - divisions of penial appendix; C- caecum; E- epifallus; F-flagtllum; P-penis; $\mathrm{R}$ - reproductive retractor; $\mathrm{Sr}-$ spermathecal reservoir; $\mathrm{Sd}$ spermathecal diverticle; Uva- upper- division of vagina; Lvalower division of vagina. 